of the third day he had experimented sufficiently to be convinced that we have only to see a thing for long enough in a given place to imagine we feel it there also. He concludes that if we had been so constructed that we always saw our bodies a hundred yards away we would feel them there also. In fact a spacial harmony between the two senses can grow up under a vast variety of conditions, provided that the experience be sufficiently uniform. From his results, it appears likely that normal reactions are developed in a similar way. But this fact does not alter the conclusions arrived at in the paper.

One must be cautious about applying conclusions drawn from an experiment dealing with reactions, to a. problem dealing with origins.

\title{
REFERENCES
}

1. Fraser.- “ Selections from Berkeley," p. 135, 1874.

2. Fraser. - Op. Cit., p. 142.

3. Quoted from-GRANT.-Psychological Optics, p. 116, 1938

4. ALCKE.-Essay on the Understanding, Bk. II, Cap. IX, 1690.

5. Philosophical Transactions, 1728.

6. Raehlmann.-Zsch.f. Psych. u. Physiol. d. Sinnesorg, 1891.

7. NUNNELEY.-Organs of Vision, pp. 30-33, 1858.

8. Franz.-Philosophical Transactions, 1841.'

9. LatTa.-Brit. Jl. of Psychól., Vol. I, 1905.

10. Fisher.-Ophthal. Rev., 1914.

11. Clarke MURRAY.-Hand Book of Psychology, p. 170, 1892.

12. Stratton.-Experimental Psychology, p. $131 \mathrm{ff}, 1903$.

13. Parsons.-Introduction to the Theory of Visual Perception, p. $157 \mathrm{ff}$.

14. Hamilton, W.-Léctures on Metaphysics, Vol. II, xxviii, 1858.

15. GRANT. Op. Cit., p. 118.

16. JAMES, W.-Principles of Psychology, Vol. II, Chap. XX, 1890.

17. Parsons.-Op. Cit.

18. DUKE-ELDER.-Text-Book of Ophthalmology, Vol. I, p. 1060.

19. VERNON.-Visual Perception, p. 64, 1937.

\section{THE EFFECT OF THE DURATION OF STIMULUS ON THRESHOLD MEASUREMENTS IN THE DARK ADAPTED EYE**}

\author{
BY V,
}

Simon YudKIN, Ph.D., M.B., M.R.C.P., Flight-Lieut., R.A.F.v.R. FROM R.A.F. INSTITUTE OF PATHOLOGY AND TROPICAL MEDICINE

\section{Intfoduction}

INSTRUMENTS used for the determination of dark adapted rod thresholds incorporate a test light which is either continuously illuminated (Craik \& Vernon, 1941, S. Yudkin, 1941) or exposed as a flash of definite duration. The duration of flash used in the latter type of instrument varies, however; for example, Wald and

\footnotetext{
* Received for publication, August 22, 1944.
} 


\section{SIMON YUDKIN}

Steven (1939) use exposures of 0.02 second, Hecht and Schlaer (1938), exposures of $0 \cdot 2$ second, and Stiles (1943), exposures of 0.8 second. The instrument designed for use in the Royal Air Force incorporates a camera shutter the speed of which can be varied, and in 1942 the effect of variation in the duration of exposure was studied.

\section{Methods and Procedure}

The test light of the instrument (see Fig.) is an opal disc $\frac{1}{2}$ inch in diameter illuminated from behind by a 6 volt 3 watt. bulb activated by accumulators. The brightness is reduced to the order of that required by the dark adapted eye by a dense " neutral ."

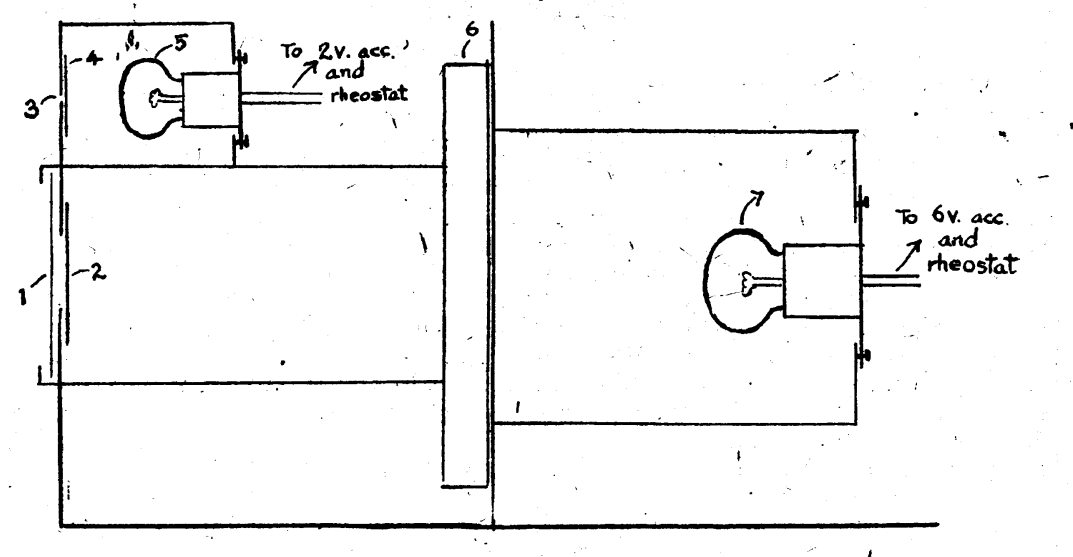

ROYAL AIR FORCE ADAPTOMETER.

1. "Neutral" Filter "Opal Glass Plate covering opening of test patch.

3. Fixation spot.

4. Dark red Wratten filter.

5. 2 v. 1:5 watt lamp for fixation spot.

6. Camera shutter.

7. $6 \mathrm{v}, 3$ watt lamp for test light.

filter (transmission 0.069 per cent.) placed in front of the opal disc. It is then varied over the necessary range by a graduated rheostat which,' with a voltmeter, is connected in the circuit. Only small movements of the rheostat are required and the colour of the test light remains practically constant. A camera shutter is interposed between the bulb and the opal disc so that the test light can be exposed for different durations. A small fixation spot of dim red light is placed $1 \frac{1}{2}$ inches above the centre of the test light and is illuminated by, a separate bulb and circuit. It is kept at just visible brightness during the test by a rheostat in the circuit. The fixation spot and test light are viewed through a tube' 12 
inches long fixed to the front of the instrument. The area of retina thus tested is of visual angle $2 \cdot 3^{\circ}$ and the centre is $7^{\circ}$ abbve the macula.

The test is carried out as follows. Five subjects are instructed to wear goggles fitted with dark-green glass of transmission about 4 per cent. and are kept in a dimly lighted room for 20-25 minutes. They are then taken to the dark room where they remain for a further 25 minutes. During this time a short explanation of the procedure of the test is given. The first subject then sits at the instrument and views the fixation spot with both eyes open. The test light is adjusted to a fairly high brightness and one or two exposures made. It is then flashed on at intervals of about 4 seconds, and the subject states " seen " or " not seen " for, each flash. A short rest is allowed after about every twenty exposures: The brightness of the test light is gradually reduced until one flash is " not seen "; it is then gradually increased until a flash is " seen " and once more reduced in small steps until three consecutive negative responses are obtained at one level of brightness. The reading on the graduated rheostat is recorded. The other four subjects follow, and then all are tested again. The mean of the two readings for each subject is regarded as the final rod threshold for that individual.

The experiment was carried out on about 600 airmen at an R.A.F. Station in England. The dark adapted rod thresholds of these men were measured on each of three occasions at intervals of three weeks. On each occasion the threshold of each man was measured using two different periods of exposure. One of these was 0.2 second, the other was $0.02,0.04,0.1,0.5$ or 1 second, the same two exposures being used for each man for all three tests. Thus all the men were tested with the 0.2 second exposures and about 60-115 men with each of the. other exposures. Some of the men were not available for all three tests and some were tested only with the $0 \cdot 2$ second exposure.

During the intervals between the tests the men received various vitamin or dummy tablets. No specific effect on the thresholds was produced by any of these supplements, however*, and the results for each exposure time may thus be considered independently of the treatment given.

\section{Results}

Table I shows the mean threshold values and standard deviations for the different durations of exposure of the test light. For each exposure the mean and standard deviation of the thresholds of the same men tested with a $0 \cdot 2$ second exposure is also given.

* There was a slight but significant improvement in all groups, due apparently to a "learning" effect (see also Tables II and III) but no difference between the groups receiving different supplements. 
It is seen that the mean threshold is lower with the longer durations but the change is not proportional to the increase in duration. Between the 0.5 and 1 second exposures, indeed, there is no further lowering of the threshold. The range of the threshold values of the groups tested with each duration does not differ significantly and is about one $\log$ unit.

The thresholds of most of the men varied somewhat from test to test. The amourt of variation, unlike the range of the thresholds, differed according to the duration of exposure of the test light (Tables II and III). This variation is least for the 0.2 second exposures for both the 1st-2nd and 2nd-3rd tests although many of the differences are not significant. The results for all the tests

- TABle I.-Rod Thresholds for Different Durations of Exposure of Test Light

\begin{tabular}{|c|c|c|c|c|c|c|c|c|c|c|}
\hline $\begin{array}{l}\text { Duration of flash } \\
\text { (seconds) }\end{array}$ & 0.02 & 0.2 & 0.04 & 0.2 & 0.1 & 0.2 & 0.5 & 0.2 & 1 & 0.2 \\
\hline Number tested & 115 & 115 & 109 & 109 & 107 & 107 & 122 & 122 & 88 & 88 \\
\hline $\begin{array}{l}\text { Mean threshold } \\
\quad \text { in } \log \mu \mu_{1} \ldots\end{array}$ & $4 \cdot 284$ & 3. 577 & $3 \cdot 956$ & $3 \cdot 615$ & 3.818 & 3.639 & $3 \cdot 415$ & 3.549 & 3.452 & $3 \cdot 580$ \\
\hline $\begin{array}{c}\text { Standard Devia- } \\
\text { tion } \quad \cdots \quad \cdots\end{array}$ & $\cdot 129$ & $\cdot 141$ & $\cdot 173^{\circ}$ & $\cdot 145$ & $\cdot 158$ & $\cdot 165$ & $\cdot 165$ & $\cdot 154$ & $\cdot 151$ & $\cdot 140 \stackrel{8}{\frac{0}{2}}$ \\
\hline $\begin{array}{l}\text { Difference } \\
\text { between S.Ds. }\end{array}$ & $\cdot 012 \pm$ & $=\cdot 013$ & $027 \pm$ & $=\cdot 015$ & $\cdot 007 \pm$ & $=016$ & $011 \pm$ & $=014$ & $\cdot 011$ & 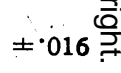 \\
\hline
\end{tabular}

TABLE II.-Changes in Thresholds Between 1st and 2nd Tests

\begin{tabular}{|c|c|c|c|c|c|c|c|c|c|c|}
\hline $\begin{array}{c}\text { Duration of flash } \\
\text { (seconds) }\end{array}$ & 0.02 & 0.2 & 0.04 & 0.2 & 0.1 & 0.2 & 0.5 & 0.2 & 1 & 0.2 \\
\hline Number tested & 115 & 115 & 62 & 62 & 68 & 68 & 1.14 & 114 & 83 & 83 \\
\hline $\begin{array}{c}\text { Mean change log } \\
\mu \mu 1\end{array}$ & -0152 & -.0052 & -0416 & -0312 & -021 & -0258 & +026 & $+\cdot 0204$ & -0170 & $0+0010$ \\
\hline 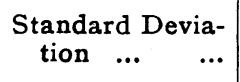 & $\cdot 150$ & $\cdot 126$ & $\cdot 172$ & $\cdot 140$ & $\cdot 162$ & $\cdot 133$ & $\cdot 149$ & $\cdot 121$ & $\cdot 133$ & $\cdot 132$ \\
\hline $\begin{array}{l}\text { Difference be- } \\
\text { tween S.Ds. } \\
\text { Difference be- } \\
\text { tween S.Ds. } \\
\text { (using all } 0 \cdot 2 \\
\text { second to- } \\
\text { gether) (S.D. } \\
=128 \text { ) }\end{array}$ & $\cdot 024=$ & $\pm \cdot 013$ & $\begin{array}{l}032^{\circ} \\
V\end{array}$ & $\pm \cdot 020$ & 029 & $\pm \cdot 015$ & .021 & $\pm \cdot 011$ & $\cdot 001$ & $\pm: 011$ \\
\hline
\end{tabular}


EFFeCT OF THE DURation OF STIMULUS ON THRESHOL̃d

MeAsurements in The Dark AdAPTED Eye

TABLE III.-Changes in Thresholds Between 2nd and 3rd Tests

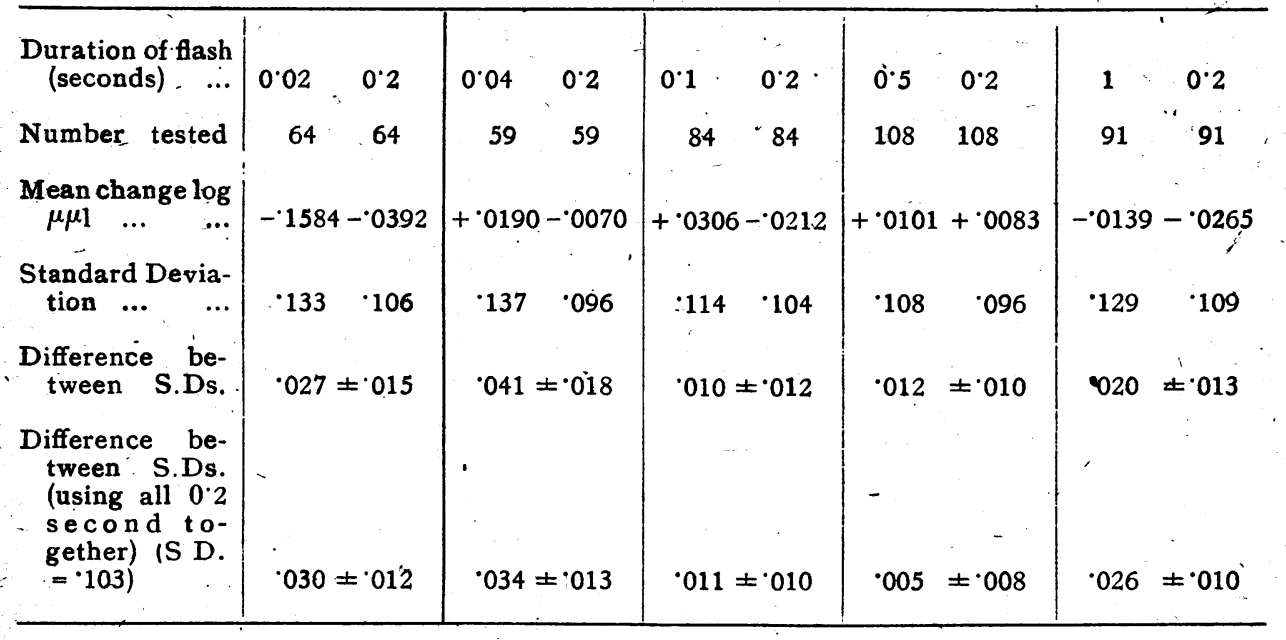

with the 0.2 second exposure may be combined as they are very -similar and then the differences between the $0 \cdot 2$ second and most of the other exposures become statistically significant. It may be noted that the changes between the 2nd-3rd tests are less for all durations than those between the 1 st and $2 \mathrm{nd}$; this is probably due to a " learning " factor.

\section{Discussion}

a. Relationship of mean threshold to duration of exposure.The relationship between the duration of stimulus and threshold levels depends in part on the size of the test field (Graham and Margaria, 1935). With very small parafoveal fields the threshold varies inversely as the duration of stimulus over a certain range; as the durations become longer there is a fairly abrupt change so that the threshold hardly changes with increasing duration. When larger fields are used the abrupt change does not occur; instead the threshold decreases continuously, but not proportionally, with increasing duration.

The results given here are in broad agreement with those of Graham and Margaria for the lárger test fields. These authors explain the absence of the abrupt change as due to an increasing proportion of neurones with only partial overlap from other. stimulated neurones as the field becomes larger, with incomplete summation in these neurones. Another consideration seems equally important, however. The maximum length of time for which the eye can remain fixated is probably about $0 \cdot 2$ seconds. When the test light is exposed for 1 second, say, it may be fixated 
for 1,2 or 3 periods of 0.2 seconds. Now, Hecht, Schlaer and Pirenne (1942) have re-emphasised (see also Stiles, 1939) that at brightnesses near the threshold level there is no definite brightness above which the test light is always seen and below which it is never seen but a gradually increasing proportion of negative responses as the brightness is reduced. With an exposure longer than 0.2 seconds, therefore, the light may in effect be exposed more than once and if even one of these exposures is seen, a positive answer will be given. The proportion of positive responses will thus tend to be greater than when $0 \cdot 2$ second exposures are used and the threshold measured as described above will tend 'to be lower with the 0.5 or 1 second exposure than with the 0.2 second exposure.

Again, the reaction time of the eye is about 0.2 seconds (Duke-Elder, 1938) so that with stimuli of longer duration than this there is time for fixation to be lost and for a different and possibly more sensitive part of the retina to be stimulated. This also would tend to lower the threshold with longer durations.

$b$. Range of thresholds in groups of subjects tested with different durations of exposure.-The range of thresholds seems to be a characteristic of the population and not to depend on the exact method of measurement (see also Hecht and Mandelbaum, 1939). It is similar when a continuously illuminated test light is used (Yudkin, Robertson and Yudkin, 1943). This means, in effect, that when individual readings are less important than the mean value and standard deviation of the thresholds of a population as a whole (e.g., in nutrition surveys) any consistent duration of exposure may be used.

c. Variability of individual thresholds with different durations of exposure.-The considerations concerning the fixation and reaction times of the eye help also to explain the greater variability of the thresholds with exposures longer than $0 \cdot 2$ seconds. As the light may be seen one or more times with these longer exposures and as different parts of the retina may be stimulated during the exposure the apparent threshold will be likely to vary a good deal from test to test.

With the exposures shorter than $0 \cdot 2$ seconds the red light may not be fixated at all during the exposure and different portions of the retina may be stimulated with each flash. In addition slight variations in the speed of the shutter affect threshold levels markedly when the exposures are short but very little when they are longer than $0 \cdot 2$ seconds (Graham and Margaria loc. cit., and Table I). As the shutter used in this experiment was an ordinary camera shutter these variations in speed may have accounted in part for the greater variability of the thresholds with the 0.04 . and 0.02 second exposures. 


\section{EFFECT OF THE DURATION OF STIMULUS ON THRESHOLD MEASUREMENTS IN THE DARK ADAPTED EYE}

With the 0.2 second-exposure the light may be seen for all or part of that time; there is no time for the wrong portion of the retina to be stimulated, however, and slight differences in the exposure time are of little consequence at this duration, so that inaccuracies of the shutter will not be important. It would seem then that on both theoretical and practical grounds 0.2 seconds is the most suitable duration of exposure of-the test light for repeated measurements of the dark adapted rod thresholds.

\section{Summary and Conclusions}

Five groups of $60-115$ men were tested on each of three occasions. The dark adapted rod thresholds of all the men were measured using a test light exposed in flashes of $0 \cdot 2$ second duration. In addition the thresholds of the men in each of the groups were tested with a test light exposed in flashes of one of the following durations : $0.02,0.04,0.1,0.5$ or 1 second.

The following results were obtained.

1. The mean threshold was lower for the longer durations up to 0.5 seconds but the lowering of threshold was not proportional to the increased duration of exposure.

2. The range of thresholds for all the groups was the same whatever the exposure.

3. The variability of individual thresholds from test to test was least with the 0.2 second exposure and more for all the other exposures.

The results given here are probably applicable to all measurements of threshold values made with similar instruments.

Acknowledgments. - I am indebted to Dr. Bradford Hill for help with the statistical analysis of the results and to the Com. manding Officer, officers and men of the Station who assisted in the arrangements or took part in the tests.

\section{REFERENCES}

CraIK, K. J. W. and Vernon, M. D. (1941).-Brit. Jl, Psychol., Vol. XXXII, p 62.

DUKE-ELDER, W. S. (1938).-Text-book of Ophthalmology. Henry Kimpton.

GrahaM, C. H.' and Margaria, R. (1935).-Amer. Jl.'Physiol., Vol. CXIII, p. 299.

Hecht, S. and Mandelbaum, J. (1939).-Jl. Amer.' Med. Assoc., Vol. CXII, p. 1910.

Hecht, S. and Schlaer, S. (1938) -Jl. Opt. Soc. Amer., Vol. XXVIII, p. 269.

Hecht, S., Schlaer, S. and PIRenNel M. H. (1942).-Jl.Gen. Physiol,, Vol. XXV, p. 819.

Stiles, W. S. (1939).-Pròc. Roy. Soc. (B), Vol. CXXVII, p. 64.

(1943).--Personal communication.

WaLd, G. and Steven, D. (1939).-Proc. Nat. Acad. Sci., Vol. XXV, p. 344.

YUDKIN, J., ROBERTSON, G. W. and YUDKIN, S. (1943).-Lancet, Vol. I, p. 10.

YUDKIN, S. (1941). -Brit.Jl. Ophthal., Vol. XXIV, p. 231. 